\title{
APONTAMENTOS DE UM TRADUTOR DE TOLSTOI
}

\section{Noé Silva*}

RESUMO: No artigo, o autor discute alguns problemas específicos da tradução do russo para o português, entre os quais o da repetição constante de palavras no texto original, bem como o emprego mais generalizado das formas modais do verbo e de orações impessoais. Apesar da ênfase no conteúdo, o autor discute as várias possibilidades de transmissão do sentido do original, com exemplos do romance "Ressurreição" de Tolstói.

UNITERMOS: Tolstói; tradução; participio; gerúndio; orações impessoais

ABSTRACT: The author deeply discusses the problem of constant repetition of words, the more generalized use of modal forms of the verb, and impersonal sentences. In spite of the primacy of content considered by the author, he analyzes various possibilities of expressing the original sense with examples taken from Liev Tolstoy's novel "Resurrection".

KEYWORDS: Tolstoy; translation; particple; gerund; unpersonal phrases

* Professor Doutor do Departamento de Letras Orientais - FFLCH/USP. 
Apresentam-se alguns problemas da tradução do romance "Voskressiénie", de Liev Tolstói. Quem traduzisse outro clássico do idioma de "O capote" e "Crime e castigo" enfrentaria as mesmas dificuldades. A primeira não poderia ser outra, que não a ausência de artigos na língua russa. Assim, o título da obra poderia ser "A ressurreição", "Uma ressurreição" e, ainda, pura e simplesmente, "Ressurreição", sem artigo. Somente a leitura das suas quase quinhentas páginas resolve a questão em favor da terceira alternativa. Pois vejamos. Diz-se "as cruzadas" e "o Romantismo", porque se supõe que todos saibam dessas expedições armadas e desse movimento artístico; "a ressurreição", por sua vez, pediria um complemento, como acontece em "o descobrimento (de que?) da América, da penicilina"; como o título do original não diz de que ressurreição se trata, exclui-se a alternativa com o artigo definido. A segunda, com o indefinido, também não se sustenta, pois, extremamente redutora, faz o leitor pensar na ressurreição de uma pessoa ou de uma coisa, quando, no romance, se insinua a idéia de ressurreição muito além da esfera individual - a idéia da necessidade de regeneração da Humanidade toda, dos seus costumes e das suas bases morais (pensamento magistralmente expresso, já na primeira página, com a contraposição entre as atitudes e até os odores da Humanidade toda e os passos e aromas da Primavera-esta, por si só, já sinônimo de "renascimento"). No nosso raciocínio, partimos da análise dos dados do original russo; portanto, nem por um segundo consideramos a chamada "tradição estabelecida" pelas traduções indiretas da obra, já que somos do entender que tais "traduções" constituem um engodo para apanhar incautos e um estímulo à ignorância.

Depois de pronto um trecho, coloca-se um artigo cá, tirase outro acolá, num trabalho muito semelhante ao de um músico, que, várias vezes, para a afinação do seu instrumento de corda, aperte uma cravelha, afrouxe outra e tire algumas notas. A delicadeza da questão pode ver-se dos exemplos.

O primeiro emprego de Máslova, a personagem central, é na casa de um stanovói. O dicionário Russo-Português dá: comissário de polícia rural. Surge imediatamente a pergunta: a que substantivo se refere o adjetivo? A polícia? Não. Primeiro, porque, na Rússia, não existia nenhuma polícia rural. Segundo, 
porque, se o adjetivo se referisse a polícia, esta exigiria o artigo definido: comandante da policia florestal, oficial da policia montada, que é como se fala em português. O adjetivo, portanto, modifica comissário. O significado "comissário de polícia rural" é insatisfatório e induz o tradutor em erro, já que nenhum comissário é rural, do mesmo modo que ninguém é delegado federalde polícia, mas delegado da polícia federal.

Stanovói é abreviatura de stanovói prístav. Prístav significa "comissário, chefe da polícia" e o adjetivo stanovói vem de stan ("subdivisão administrativo-policial de um concelho", segundo o Dicionário da Lingua Russa, de S. I. Ójegov). Stanovói prístav é, por conseguinte, o nome dos comandantes da polícia na província, no meio dito rural. Resolvemos deixar o termo russo no texto e explicar o seu significado em nota de roda-pé: "chefe da Polícia nos concelhos da Rússia de então".

O exemplo mostra bem as dificuldades, criadas pelo artigo ou pela sua ausência. Mais um de entre muitos: a personagem Nekhliudov levanta-se e vai lavar-se:

tchísto vúmyv rúki aromátnym mýlom [depois de lavar as mãos com um sabonete perfumado]

Pode perfeitamente ser, também: com sabonete perfumado. Essa alternativa privilegia o produto, com que se lavam as mãos. Omite-se o artigo, sempre que se põe em primeiro plano a idéia genérica da coisa, que desempenha a função sintática de adjunto adverbial de instrumento: lavar-se com água fria; escrever a lápis etc. Pareceu-nos, porém, no exemplo, mais conveniente individualizar tal coisa e, por isso, dar-lhe o artigo indefinido, porquanto pode haver sabonetes não perfumados.

on nadiél tchístoie výglajennoie bel'ió [vestiu roupa de baixo limpa e engomada]

Roupa de baixo com artigo ou sem ele? A dificuldade, aqui, cria-se pelos adjetivos. Sem eles, seria simplesmente: a roupa de baixo. Ou não se diria: 
spustiv s krováti gládkie biélye nógui, nachol ími túfli [pôs os pés brancos e macios no chão, colheu com eles os sapatos].

Sapatos representam coisas que todos, supostamente, têm e usam; por isso o artigo definido. Se o acrescentássemos à roupa de baixo, teríamos de separar, por vírgula, os adjetivos do substantivo, porque designariam qualidades permanentes desse tipo de roupa, características a ele inerentes, ao menos no momento de vesti-los: a roupa de baixo, limpa e engomada. Estariam realçadas as qualidades do objeto, o que não se faz no original russo: os adjetivos vêm na sua posição normal em relação ao substantivo, ou seja, antes dele.

Tem-se a alternativa uma roupa de baixo limpa e engoma$d a$. Pode individualizar-se uma peça (uma camisa, um par de meias etc.) da roupa de baixo, mas esta não, porque representa um todo uno e indivisivel, um conjunto, a saber, a reunião de camisas, meias, cuecas, ceroulas etc., do uso próprio de homem ou de mulher. Portanto, impõe-se a idéia genérica do objeto, que repele o uso de artigo e fundamenta a nossa escolha por roupa de baixo limpa e engomada.

O nosso sentido da língua deve estar apurado, para, amparado pelo contexto, fazer os ajustes exigidos pelo original. Isso vale também para o problema da pontuação. Há os casos óbvios, em que uma língua exige o emprego da vírgula e a outra a rejeita, como no seguinte exemplo, tirado do início do romance de Tolstói:

liudi chtchitáli, chto sviachtchenno i vájno... [as pessoas julgavam que sagrada e importante fosse...]

A conjunção "chto", equivalente russa da conjunção subordinativa integrante "que", é sempre precedida por vírgula. Encontram-se situações mais sutis, em que as vírgulas russas não correspondem exatamente às portuguesas, e isso suscita a questão do ritmo da frase. Tolstói tende a períodos compostos, com muitas orações. Enuncia-se um fato com as suas causas, conseqüências e circunstâncias: 
Ela empregou-se como criada de quarto na casa de um stanovoi, mas pôde viver nela somente três meses porque o comissário, um velho de cinqüenta anos, se pusera a assediá-la e, uma vez, em que ele se esmerara nas iniciativas, ela ferveu com raiva, chamou-lhe idiota e diabo velho e empurrou-o pelo peito com tanta força, que ele caiu.

Nós procuramos sempre manter a estrutura desses trechos longos, sem jamais quebrar com o ponto tais períodos em dois; com isso, tentamos preservar o máximo das formas primitivas dos conteúdos. Não ignoramos, porém, que, em alguns casos, a intervenção do tradutor possa e talvez deva ser mais decisiva; está investido do poder, a ele outorgado pelos leitores desconhecedores do idioma do original, e deve levar-lhes a informação da maneira mais leve possivel. Assim, entendemos que, cá e lá, o tradutor tem o direito de proceder como acha mais conforme com a índole do idioma de chegada.

Em algumas dessas situações, de períodos longos e com muitas orações, a nossa interferência limitou-se à troca da vírgula pelo ponto-e-vírgula. Dentre os muitíssimos exemplos, que se poderiam respigar no romance de Tolstói, vêm bem a calhar o seu primeiro parágrafo. Cumpre assinalar que o original russo contém um único ponto-e-vírgula, a saber, depois da frase, que na nossa tradução termina em rebentavam:

Por mais que as pessoas, reunidas às centenas de milhares em um sítio pequeno, se empenhassem em desfigurar a terra em que se apinhavam; por mais que cravassem pedras no solo, para que nele nada crescesse; por mais que extirpassem toda e qualquer ervinha, que rompesse por entre elas; por mais que impregnassem o ar do fumo de carvão de pedra e petróleo; por mais que podassem as árvores e afugentassem todos os animais e aves, a Primavera era Primavera inclusivamente na cidade. O Sol derramava o seu calor; a erva, tornando à vida, crescia e verdejava em todos os lugares, de onde a não haviam raspado, não apenas nos relvados das alamedas, senão também entre as lajes de pedra; as bétulas, os álamos e a cereja galega deitavam as suas odoriferas e pegajosas fo- 
lhas; as tilias tumesciam os gomos, que rebentavam; as gralhas, os pardais e os pombos, com a alegria primaveril, preparavam já os seus ninhos, e as moscas, aquecidas pelo sol, zuniam junto dos muros.

A oração principal do primeiro período é precedida por cinco orações subordinadas (cinco adverbiais concessivas, uma adjetiva restritiva e uma adverbial final), separadas, no original russo, por mera vírgula. Em português, tal não é a pontuação mais apropriada. Com a pausa maior, proporcionada pelo ponto-evírgula, atenua-se a monotonia da repetição da conjunção "por mais que". Há, também, outra razão para a escolha do ponto-evírgula: a pausa, por ele dada, é o espaço da vanidade da ação do sujeito das subordinadas adverbiais concessivas e representa o espaço do triunfo do sujeito da oração principal. Tolstói pôs a Primavera a cavaleiro das ações da Humanidade, e o ponto-evírgula, usado como fecho das orações concessivas, predispõe melhor o leitor para a passagem do discurso sobre as atitudes humanas para um valor mais alto, que a elas se contrapõe vantajosamente, na ação sobre o mundo.

Tolstói escreve tal qual fala o pregador; as frases sucedem-se como as marretadas do ferreiro na peça, trabalhada na bigorna; o leitor que tire as suas conclusões, depois dos argumentos, apresentados de enfiada, num trabalho, primeiro, de assimilação das coisas ditas e, segundo, de ponderação delas. A nossa intervenção não vai de encontro a essa característica do citado trecho tolstoiano; vai,sim, ao encontro da sua intenção maior, que é dizer o pouco que podem as parvoíces dos homens contra a regular e segura marcha da Natureza; ao substituir a vírgula, o ponto-e-vírgula permite melhor sopeso das palavras e dá mais peso, confere mais relevância, ao que se afirma em contraposição ao que vem nas orações subordinadas adverbiais concessivas. A oração principal é como uma nota de natureza oposta à daquelas e não deve, portanto, ser lida de cambulhada com as outras, mas após uma pausa. Os cinco primeiros verbos designam ações humanas contra a Natureza, insanas e terríveis, mas incapazes de impedir o triunfo da Primavera; têm-se orações que, pela extensão, exigiriam, na leitura (ao menos aos 
nossos ouvidos lusófonos), uma pausa maior do que a sugerida pela simples vírgula do texto russo. Por outros termos: o citado trecho de Tolstói, visto como uma peça musical, ganha, se tocado em ritmo mais lento. Mas faça cada qual o seu próprio juízo, lendo o trecho supra-reproduzido com vírgulas no lugar dos pontos-e-vírgulas da nossa tradução.

Agora passemos, dentre vários assuntos, aos dois mais importantes ao nosso ver. O tradutor, dotado da consciência do limite da sua autonomia, deixa o máximo do autor no texto, contrariando apenas minimamente a índole do idioma de chegada. Não falamos do conteúdo das frases, mas dos meios lingüísticos, usados para a sua expressão. Nisso, os autores russos dão muito trabalho.

Uma questão, a repetição de palavras, está relacionada com o estilo; a outra, o emprego das formas modais do verbo, reflete uma característica da língua russa.

A primeira não escapa nem a quem não tenha muita intimidade com boa literatura em língua portuguesa. As palavras repetidas em frases muito próximas entre si substituíram-se por convenientes sinônimos em número também apropriado. A repetência de termos constitui fato muito sério e justifica-se, em Português, somente pelo desejo ou necessidade de enfatizar algo, e Tolstói parece achar que tal se deva observar também em Russo, como o demonstra ainda o primeiro parágrafo de "Ressurreição" e o início do seguinte, em que repete quatro vezes dois adjetivos e três vezes um verbo:

Julgavam que sagrada e importante fosse, não essa manhã primaveral, não essa formosura do mundo de Deus, dada para o bem de todos o seres, formosura que predispunha a todos à paz, à concórdia e ao amor, mas que sagrado e importante fosse o que elas próprias haviam inventado para dominarem umas às outras.

Assim, no escritório da penitenciária provincial, julgavase sagrado e importante não que a todos os animais e pessoas houvessem sido dadas a comoção e a alegria da Primavera; julgava-se sagrado e importante o fato de que, 
na véspera, se recebera um papel com número, carimbo, cabeçalho e a ordem de....

Isso soa muito bem, em Russo, e em Português não fica pior, pois trata-se de um caso de repetição justificada de palavras e com mira a determinado efeito na sensibilidade do leitor. Tolstói quer fazer-nos sentir a distância existente entre a sublimidade da Natureza na quadra primaveril e as pequenezas humanas. Essa distância, estabelecida na escala moral, necessita de uma expressão no texto, dada neste por duas coisas: no sentido espacial e temporal, a repetição dos adjetivos e do verbo, com exemplificação generosa (estendida) do que é realmente sagrado e importante; no sentido ideológico, a sensação da grandiosidade, da amplitude da ação de tais coisas (essa beleza do mundo, coisa que dizemos sempre com um movimento largo de braços; formosura, que predispõe a todos à paz; comoção e alegria, que se comunicam a todos os animais e pessoas - enfim, coisas, que afetam a tudo e a todos). Em suma, os adjetivos, ao se repetirem, têm efeito emendativo, cumulativo; sinônimos simplesmente eliminariam a sensação de distância, que importa estabelecer, entre as duas coisas. Posto no plano cartesiano, isso sugere a imagem de um seixo atirado a águas repousadas; os adjetivos determinam um centro, e as frases formam círculos concêntricos; o leitor não sente nenhum fastio porque, embora aquele ponto de referência se lhe lembre regularmente, a sua atenção acompanha a expansão do pensamento do autor.

Tolstói, porém, nem sempre age assim, e repete termos na mesma linha ou em linhas seguidas, deixando o texto com rebarbas. A história de Katiucha Máslova começa assim:

Istóriia arestántki Máslovoi bylá ótchen obyknoviénnaia istóriia [A história da prisioneira Máslova era uma história muito comum]

A frase, na sua tradução literal, até passaria, mas fica melhor desta forma: "A história da prisioneira Máslova era muito comum”. Sem nenhuma repetição desnecessária. 
Mais adiante, temos um histórico das relações de Máslova e do príncipe Nekhliudov e outro exemplo corroborador da nossa tese:

Vira Katiucha pela primeira vez, quando, no terceiro ano da Universidade, a preparar a sua tese de colação de grau sobre a propriedade da terra, passou o Verão na casa das tias. Habitualmente, passava o Verão com a mãe e a irmã nos arredores de Moscovo, na propriedade materna. Mas, naquele ano, a irmã casara-se e a mãe partira para uma estação de águas termais do exterior. Nekhlíudov tinha de escrever aquele trabalho e decidiu, assim, passar o Verão na herdade das tias.

A má impressão, causada pela repetição das palavras, só não é maior por graça da extensão do período. Podemos, sem perda de conteúdo, substituir o termo "Verão" pelo pronome obliquo correspondente (Habitualmente, passava-o com ...), e a ação "passar o Verão" por outra, que permite inferi-la logicamente (decidiu, assim, ir para a herdade das tias).

Esse tipo de repetição não passa despercebida, pois é um músculo morto no tecido do texto; não se trata de um fio de cabelo desalinhado num retrato a corpo inteiro ou uma dobra de pano mal poisada numa escultura: é entulho, que se amontoa no caminho da leitura e que se tem de transpor. Lá decidam os russos para si se isso representa uma violação às regras do bem escrever ou não; no idioma de Camões, tal é desleixo estilístico, algo inaceitável, e ponto final. Exige-se a intervenção do tradutor, que tem de aproximar-se do leitor culto da lingua de chegada.

Deve ter-se, por outro lado, o máximo de cuidado com os sentimentos e intenções, carregados pelas palavras. No próximo exemplo, o nosso primeiro ímpeto é bradar contra o efeito deletério das repetições, mas, para além de excessos, a frase contém uma intenção. Tolstói, depois de afirmar que a caserna destruíra o que Nekhliudov tinha de bom, escreve: 
V ossóbennosti razvrachtcháiuchtche diéstvuiet na voiénnykh takáia jizn potomu, chto, iésli nevoiénnyi tcheloviék vediót takúiu jizn, on v glubinié duchi nie mojet nie stydyttsa takoi jizni [De modo particularmente depravador age nos militares tal vida, porque, se um não militar levasse tal vida, ele, no fundo da alma, não poderia não envergonhar-se de tal vida].

Folga comentar o horror que seria tal período no nosso idioma, se deixado em estado bruto. Inicialmente, a nossa tradução trazia um sinônimo: semelhante existência. Como ex-oficial do Exército czarista, Tolstói conhecia muito bem o quotidiano da caserna, e cada "tal vida" representa uma espécie de vergastada de exprobração desse modo de viver, cujo vigor o referido sinônimo simplesmente anularia. Repôs-se, assim, o substantivo "vida", na segunda aparição e, para a preservação do efeito do original, o pronome "tal" substituiu-se pela expressão "uma... dessas", dotada de um matiz de condenação bem explícito; por fim, na terceira aparição, entrou o pronome pessoal, bem à feição da nossa língua:

Tal vida age de modo particularmente depravador nos militares porque um não militar, se levasse uma vida dessas, não poderia não envergonhar-se dela, no fundo da alma.

Em muitos casos de repetição de palavras, basta a simples omissão dos termos óbvios:

A criança tinha três anos, quando a mãe adoeceu e morreu. Era um peso muito grande para a avó, e então as velhas senhoras tomaram-na ao seu cuidado. A menina de olhos negros saiu extraordinariamente vivaz e graciosa, e as velhas [senhoras] encontraram nela o seu consolo.

[As velhas senhoras] Eram duas: a menor, mais bondosa, Sófia Ivánouna, foi quem a batizara; a maior, mais severa, Mária Ivánouna. 
Na segunda aparição, o substantivo "velhas", como o substantivo "militar" no outro exemplo, podia muito bem substituirse por um sinónimo. Por que não o fizemos? Porque queriamos preservar, na tradução, o máximo do estilo do autor ou, mais exatamente, queríamos deixar o máximo de um traço do estilo do escritor, na medida tolerável pela língua portuguesa.

Já o problema da tradução de frases com verbos nas formas modais (particípio e gerúndio) não permite o artifício da elipse. O único socorro são as substituições e os acréscimos.

Todos os que estudam a lingua russa conhecem a força e a beleza dos seus verbos. À parte a escassez de tempos (somente Passado, Presente e Futuro), para cada verbo nosso há, grosso modo, dois com o mesmo significado (nos aspectos imperfectivo e perfectivo), cada qual com as suas atribuições bem delimitadas. E quê dizer dos participios?!

Do particípio passivo não falaremos, uma vez que não nos oferece nenhuma novidade e, na tradução, não causa constrangimentos:

Tchúvstvuia naprávlennye na sebiá vzgliády, arestántka nezamiétno, nie povorátchivaia gólovu, kossílass' na tiekh, kto smotriél na niió, i éto obrachtchónnoie na niió vnimánie vselílo ieió. [Sentindo os olhares dirigidos a ela, imperceptivelmente, sem virar a cabeça, mirava com o rabo do olho para os que a olhavam, e essa atenção, a ela prestada, alegrava-a.]

O particípio ativo apresenta impressionante vitalidade, embora mais próprio à linguagem escrita do que à falada. Conjuga-se no Presente e no Passado, e possui características também de adjetivo, variando em gênero e número, também declinando-se. Exemplos do primeiro parágrafo do romance:

... kak ni zabiváli kamniámi ziémliu, chtóby nitchevó nié rosló na niéi; kak ni stcháli vsiákuiu probiváiuchtchuiussia trávku. [... por mais que cravassem pedras no solo, para que nele nada crescesse; por mais que extirpassem toda e qualquer ervinha, que rompesse por entre elas] 
É sempre grande a tentação de traduzir o participio ativo por um adjetivo em "-ante, -ente, -inte" ou "-or"; aqui, "nascente", "despontante". Os verbos "nascer" e "despontar", porém, não têm toda a carga semântica do verbo russo; formado pelo radical "bit" (bater) e o prefixo "pro" (indicador de ação realizada através de, por entre), deixa muito claro que a erva tem de bater-se com as pedras para vencer a sua camada e dar brotos. Vem em nosso auxílio o verbo "romper", com os seus significados não somente de "nascer", "brotar" e "surgir", senão também de "abrir caminho por", "arrostar um obstáculo" e "vencê-lo com ímpeto, esforço": "que rompesse" (por entre elas é acréscimo nosso). "Rompente", aqui, não caberia, até porque se usa muito pouco o particípio ativo presente em português, em vista da preferência conferida às formas analíticas.

Lipy naduváli lopávchiessia pótchki [as tílias tumesciam os gomos, que rebentavam]. (vch - sufixo do participio passado; ie - terminação do caso nominativo plural; sia partícula reflexiva)

As orações russas com particípio ativo, como pode ver-se, dão quase sempre, em português, orações subordinadas adjetivas restritivas com o pronome relativo que. Não há nenhum problema, quando essas últimas não aparecem muito próximas umas das outras:

Jivia $v$ kvartíre, nániatoi pissátelem, Máslova poliubila prikáztchika, jivchevo na tom je dvorié. Oná samá ob iavila ob étom pissáteliu, i oná perechlá na otdiél'nuiu málenkuiu kvartíru. Prikáztchik je, obechtchávchii jenittsa, uiékhal... [Morando no apartamento, alugado pelo escritor, Máslova apaixonou-se por um caixeiro, que habitava no mesmo pátio. Ela própria referiu o caso ao escritor e mudou-se para outro apartamento, menor. Já o caixeiro, que the prometera casamento, partiu...].

Por outro lado, a substituição da construção com que deve sempre considerar-se:

TradTerm, 14, 2008, p. 123-143 
Morando no apartamento, alugado por ele, Máslova apaixonou-se por um caixeiro, morador do mesmo pátio.

Para evitarmos o som duro e desagradável do pronome relativo, truncador da frase, recorremos a substantivos e adjetivos, mas, às vezes, só a paráfrase nos vale:

Éto bylá górnitchnaia pokóinoi, nedávno v étoi sámoi kvartíre umiérchei máteri Nekhlíudova, Agrafiena Petróvna, ostávchaiassia pri sýnie v kátchestve ekonómki [Esta era a criada de quarto da falecida mãe de Nekhlíudov, que morrera naquela mesma casa, Agrafiena Petrovna, que permanecera a serviço do filho, na qualidade de governanta.]

Duas orações subordinadas adjetivas restritivas não podem aparecer tão juntas. Ademais, nessa ordenação das frases, o tal filho parece ter como mãe a criada, não a patroa; e, se não fosse o adjetivo "falecida", poderíamos pensar que a morta fosse não a princesa, mas a criada de quarto. (Em Russo, evidentemente, tudo é muito claro, pelos casos de declinação, em que os particípios e os substantivos aparecem. Os períodos, por nós citados, estão soltos, tirados do seu contexto, e isso exige maiores arranjos). A tradução tem de deixar os verdadeiros mortos em paz e os filhos com as suas verdadeiras genitoras:

Era a criada de quarto da mãe de Nekhlíudov, falecida havia pouco tempo naquela mesma casa; chamava-se Agrafiena Petrovna e permanecera a serviço dele, na qualidade de governanta.

Ao fim da segunda oração, tende-se a associar o nome Agrafiena Petrovna à mãe de Nekhliudov; por isso, usou-se um ponto-e-vírgula para devolver a atenção do leitor ao sujeito da primeira oração, "a criada". Como ilustra bem o exemplo, para além do problema do queísmo, os participios ativos russos podem trazer a promiscuidade de palavras referentes a sujeitos diversos e expor, com isso, o tradutor ao risco da deturpação do sentido das frases. 
Em relação ao gerúndio, a questão é um pouco diferente. Não há situações geradoras de construções "feias" por ele em si, mas pela quantidade, em que possa aparecer.

Não é comum, em português, o uso de tantos gerúndios de enfiada, como neste exemplo:

Obstrekáliss, ia tchai, - skazála oná, svobódnoi rukói popravliáia sbivchuiussia íubku, tiajeló dychá i ulybáiass, snizu vvierkh priámo gliádia na nievó. [Vós vos picastes com a urtiga, eu acho, \% disse ela, arrumando a saia descaída com a mão livre, ofegando e sorrindo, olhandoo diretamente nos olhos, de baixo para cima.]

O gerúndio apresenta desagradável efeito alongante da palavra e, seguido de outro, produz uma rima inoportuna. Escolhemos enfeixar com a conjunção enquanto as ações simultâneas, expressas por gerúndios; substituir uma ação pelo estado (resultado), que ela gera na pessoa (ofegando - ofegante), o que, ao fim e ao cabo, dá na mesma; e quebrar de vez a repetição do som "ã", que resistiria em enquanto - mão - ofegante olhando, pondo o último gerúndio à portuguesa:

Vós vos picastes com a urtiga, eu acho, \% disse ela, enquanto arrumava a saia descaída com a mão livre e sorria, ofegante, a olhá-lo diretamente nos olhos, de baixo para cima.

Evidentemente, é apenas numa passagem ou noutra que se deve tratar o gerúndio com rigor. Em número moderado, ocupa o seu lugar dignamente e cumpre o seu papel:

Agrafiena Petrovna, zakhvativ lejávchuiu nie na miéstie chtchótotchku dliá smetániia so stolov i perelojiv ieió na drugóie miésto, výplyla iz stolóvoi. [Agrafiena Petrovna, pegando uma escova de limpar mesa de fora do seu lugar e colocando-a em outro, saiu majestosamente da sala de jantar.] 
Há situações, em que o português pretere o gerúndio por um adjunto adverbial ou construção perifrástica, priorizando, não a ação, expressa pelo verbo, mas o seu resultado:

Nadzirátel', gremiá jeliézom, ótper zámok i, rastvoriv dvier kámery, ... kriknul [O carcereiro, fazendo tilintar os ferros, abriu o cadeado e, havendo franqueado a porta da cela, ... gritou.]

A substituição das cláusulas gerundiais depende do gosto de cada um; uma alternativa é:

O carcereiro, com um tilintar de ferros, abriu o cadeado e, franqueada a porta da cela, gritou.

Tais substituições soem tornar a frase mais seca, mais sólida. Outro fato indiscutível é que, em alguns casos, não convém traduzir o gerúndio russo como tal em português; mormente, trata-se de situações em que se fala da postura do corpo humano ou do estado de alguma parte sua (lábios, olhos, braços etc.):

Oná derjálass ótchen priámo, vystavliáia pólnuiu grut' [A mulher conservava-se ereta, projetando o peito robusto]. A mulher conservava-se bem ereta, com o peito robusto projetado à frente.]

O gerúndio vystavliáia, do aspecto imperfeito, introduz uma ação em processo, em andamento, simultânea à do verbo da oração principal.

V éto vriémia továrichtch prokuróra opiát privstal i ... sprossil, skloniv nad chítym vorotnikóm gólovu [Nesse comenos, o substituto do procurador soergueu-se de novo e ... perguntou, com a cabeça inclinada sobre o colarinho bordado].

Não se poderia dizer: "havendo inclinado a cabeça sobre o colarinho bordado". Também não se considera a possibilidade 
de "tendo a cabeça inclinada...", pois tal construção equivale a "tendo uma cabeça e ela estava inclinada...". Nesse período, a primeira oração, em termos de comunicação, representa uma obviedade do conhecimento de todos, devendo, portanto, omitirse; fica-se com a segunda, de predicado nominal, em que a palavra mais importante (núcleo) é o adjetivo (inclinada). Isso significa que mais importante do que ação do verbo "inclinar" em si é o seu resultado, patente no instante da comunicação.

... zajmúrivchiss ... skazal továrichtch prokuróra [de olhos semicerrados ... disse o substituto do procurador].

O verbo zajmúrit ${ }^{\circ}$, do aspecto perfeito, indica ação concluída e deixa, em primeiro plano, o resultado desta, isto é, os olhos semicerrados da pessoa, no momento da fala. Como nos dois exemplos anteriores, vê-se, inicialmente, a personagem e, em seguida, uma parte do seu corpo (peito, cabeça, olhos), à maneira como, no cinema, a câmera dá a visão geral de algo e, em seguida, concentra o seu foco em uma parte do objeto, aproximando deste o olho do espectador (os chamados grandes planos ou closes). Daí a escolha do adjunto adverbial de modo, em detrimento da forma verbal correspondente. Mas esclareça-se bem este ponto. Pelo fato de, aqui, o mais importante ser o resultado da ação, e não esta própria, ocorre uma espécie de metonimização, em que a ação representa o todo (a personagem), e o resultado, a parte (uma parte do seu corpo); transposto para o verbo, isso estabelece o sinal de igualdade entre, de um lado, o verbo principal (projetando) ou o auxiliar no gerúndio (havendo) e o todo e, do outro lado, o particípio (projetado, inclinado, semicerrado) e a parte. Prevalece, então, o particípio, substituído pelos adjetivos correspondentes.

Com isso, atende-se a uma regra básica da tradução, qual seja, a de que se deve verter a frase da lingua de partida com a máxima concisão, com o emprego mínimo de meios. $O$ adjunto adverbial de modo apresenta ao leitor uma ação e, ao não nomear o seu realizador, implícito, propicia economia de palavras, deixa a frase enxuta. 
Em geral, o gerúndio russo sói conservar-se em português, quando indica ação simultânea a outra, realizada pelo mesmo sujeito:

... piéred kotóroi khodili, perekátchivaiass, ... gólubi, arestántka tchut' nié zadiéla odnovó siziaká; gólub vspórkhnul i, trepechtchá krýliami... [... em frente da qual andavam, bamboleando, alguns pombos, a prisioneira por pouco não tocou com o pé um cinzento-azulado; este alçou vôo e, brandindo as asas...]

Se muito distante da oração principal, a cláusula gerundial deve traduzir-se pela subordinada adverbial correspondente, pois somente assim se estabelece a conveniente separação entre ela e as orações de outro sujeito:

Prokhodiá mímo mútchnoi lávki, piéred kotóroi khodíli, perekátchivaiass, nikiém nie obijáemye gólubi, arestantka tchut nie... [Quando passava por uma venda de farinha, em frente da qual andavam, bamboleando, alguns pombos, a quem ninguém incomodava, a prisioneira por pouco não tocou com o pé um cinzento-azulado...]

Expressando ação anterior à do verbo da oração principal, tende a traduzir-se da mesma maneira, principalmente quando os verbos estão no Passado, pois o primeiro plano cabe ao nexo temporal (seqüencial) das ações:

... gólub proletiél mímo camovó úkha arestántki, obdav ieió viétrom. Arestántka ulybnúlass i potóm tiajeló vsdokhnúla, vspómniv svoió polojéniie. [... o pombo voou bem rente ao seu ouvido, depois de afagar-lhe a face com o vento. Ela sorriu e, em seguida, suspirou profundamente, recordada da sua situação.]

Nos exemplos, aparece implícita a questão dos aspectos do verbo, o ponto mais fascinante da semântica do idioma russo e também o de mais dificil entendimento para os que o estudam. Trataremos dele em outra ocasião, dada a sua complexidade. 
Entre muitos, restou o problema das orações impessoais russas. Para gáudio dos partidários das teorias apregoadoras da impossibilidade da tradução, elas poderiam usar-se como argumento demolidor. Trata-se de uma questão de fundo históricocultural. A Rússia, situada entre o Ocidente e o Oriente, apresenta traços das civilizações de um e do outro. Pela tradição grega, nota-se, nas línguas européias modernas, o papel preponderante do eu; em primeiro plano, acha-se a individualidade, e não é por outra razão, por exemplo, que os ingleses grafam o pronome pessoal da primeira pessoa do singular com maiúscula. Já no Levante, a vida em comunidade induz o indivíduo a um forte sentimento de pertença a um grupo social, e o coletivo prepondera sobre o individual. Os russos têm esse traço oriental, que faz a pessoa, no falar, não querer distinguir-se das demais e até colocar-se em segundo plano, preferindo o uso das construções impessoais. Em português, diz-se: Eu sinto frio; em russo, preferir-se-á: É-me frio (İiå õîêîäîî; oração sem sujeito, com pronome pessoal no dativo e advérbio). Tal tipo de frase indica que a ação não é controlada pela pessoa, nem formada pela sua consciência; o indivíduo aparece como canal de expressão de uma vontade ou pensamento, ou de vazão de um sentimento, condição ou estado. Um exemplo bem esclarecedor disso é a passagem, em que Tolstói escreve que Máslova bebia para recuperar o desembaraço e o sentimento da sua própria dignidade:

Biez viná iêi vsegdá býlo unýlo i stýdno [Sem a vodca, eralhe sempre triste e vergonhoso.]

A oração russa não tem sujeito, e não se sabe o que era triste e vergonhoso para Máslova, o que a fazia sentir tristeza e vergonha. A ação apresenta-se como independente da pessoa, a qual deixa de ser sujeito para tornar-se o ser, em quem se realiza a ação ou em quem ela termina; o ser, que constitui o canal de visibilidade, expressão, da ação.

Esta não se vê como uma condição criada pela pessoa, mas como algo espontâneo, aleatório e acidental, como a erupção de um vulcão, expressão dos elementos naturais que, quando atingem determinada condição físico-química, se explicitam, sem a intermediação humana. Enfim, tem-se, no exemplo, uma 
ação, que, ainda que no mundo interior da pessoa, se realiza à revelia da sua vontade e tem a ela como seu ponto de aplicação.

Nem sempre a uma oração impessoal russa corresponde, em português, uma oração também impessoal. Na tradição ocidental, há a preponderância do eu sobre as circunstâncias do mundo objetivo, exterior, material, e a esfera do eu é impermeável à impessoalidade. Assim, a tradução da frase de Tolstói pode ser: Sem a vodca, ela sentia-se sempre triste e envergonhada. Na pouca liberdade, que nos deixa a pessoalidade obrigatória, podemos, no máximo, tirar a pessoa da condição de sujeito da oração: Sem a vodca, enchiam-na [abatiam-na, tomavam-na etc.] sempre a tristeza e a vergonha. Isto é, chega-se somente à antesala do que a construção russa dá: a impessoalidade da ação. Os russos provam cá a impessoalidade, que nós, lusófonos, experimentamos em frases como: Chove. Trovejava. Uma impessoalidade advinda do fato de que toda a declaração concentra-se na parte verbal, sem precisar apoiar-se num nominativo (Celso Luft, Gramática da Língua Portuguesa). Uma impessoalidade reinante tão-somente no mundo exterior ao do $e u$.

Como se vê, não se logra de modo algum, em português, produzir impessoalidade no universo do eu. E, fora dele, somente se a frase russa cai num dos casos de impessoalidade portuguesa. Se não cai, então, o máximo que se pode fazer é induzir o leitor à idéia do Nada e delinear a sensação da impessoalidade no horizonte da sua percepção. Entre as ações humanas absurdas e cruéis, listadas por Tolstói no início do romance, encontra-se esta:

... kak ni zabiváli kamniámi ziémliu, chtóby nitchevó nié rosló na niéi $[\ldots$ por mais que cravassem pedras no solo, para que nele não crescesse nada].

A oração russa em letras gordas é impessoal. O verbo đàñòè, que aparece no passado, vem no singular e na forma do gênero neutro, dada pelo sufixo -ëî, e o pronome indefinido iè $\div$ òî̀ ("nada") aparece no genitivo. Com a dupla negação iè ‘åãî iå e ação toda concentrada no verbo, com o esvaziamento total das noções de gênero e número, o efeito de impessoalidade é intenso. 
Como fecho deste ponto, aponte-se o fato de a impessoalidade poder conferir um matiz de fatalidade à ação, mesclado com certa lástima por algo ocorrido. Tolstói alude ao costume das famílias camponesas pobres de não alimentar as crianças, quando essas constituíam estorvo ao trabalho, e deixá-las morrer por inanição:

Tak úmerlo piat detiéi. [Assim haviam morrido cinco crianças.]

Tem-se o verbo na forma do gênero neutro (úmerlo), e piat' detiéi ("cinco crianças"), sujeito na tradução portuguesa, aparece na condição de mero adjunto adverbial de quantidade. O contexto torna a construção pessoal neutra, desapaixonada. Nenhum acréscimo ajuda a recriar, na frase da língua de chegada, o sentimento especial, gerado pela impessoalidade do verbo.

Na língua russa, há, aproximadamente, o mesmo número de casos de impessoalidade que existem na portuguesa (onze ou doze), e poderiam citar-se outros exemplos. Porém quem teve a benevolência de ler-nos até a esta linha, convenceu-se já de que não se deve levar a questão para o texto, mas, talvez, aludir a ela em prefácio ou nota de rodapé. O leitor lusófono pode, aqui ou ali, ver determinada coisa não exatamente com os mesmos matizes com que a vê o leitor russo, pois, com diferentes visões do mundo, examinam-na de pontos de vista diferentes, mas ambos enxergam essencialmente a mesma coisa. Não se deve dar importância desmedida ao problema, que é única e exclusivamente do tradutor. Podem lá os nossos colegas da Rússia, por sua vez, escrever páginas e mais páginas sobre o fato de a língua russa não possuir artigos e tantos tempos verbais, quantos os que exibe a portuguesa, mas nem por isso os seus compatriotas deixaram de comover-se com as desventuras da escrava Isaura e dos capitães de areia, e talvez até mais do que os brasileiros.

Finalmente, todos os trabalhadores honestos da tradução enfrentam problemas, sempre interessantes e desafiadores, maiores e mais específicos de acordo com o grau de afastamento do idioma de partida do português. Sabem, também, que não são comerciantes, que importem produtos exóticos e tenham de 
adaptá-lo à feição da freguesia. Se fazem concessões ao gosto vulgar de editores e não arrostam a sanha de revisores despreparados, olvidam-se de que escrever bem, num país como o nosso, é um ato civilizatório, mais do que isso, é a única atitude digna de quem não se deixou ainda contaminar pela estultice e o desmazelo da maioria dos seus concidadãos. 